\title{
Hospital: lugar para o enfermeiro cuidar do imaginário? *
}

\author{
Maria de Lourdes Castanha ${ }^{1}$ \\ Maria Ribeiro Lacerda ${ }^{2}$ \\ Ivete Palmira Sanson Zagonel ${ }^{3}$
}

\begin{abstract}
Castanha ML, Lacerda MR, Zagonel IPS. Hospital: lugar para o enfermeiro cuidar do imagi-
\end{abstract} nário? Acta Paul Enferm 2005; 18(1):94-9.

\begin{abstract}
RESUMO: Artigo que aborda relato de experiência sobre a atuação do enfermeiro como cuidador na modalidade 'Contador de Histórias', em hospital infantil. Como instrumento de cuidado, a atividade demonstra o dinamismo do imaginário, pois, mediante a fantasia das histórias, transforma a realidade vivida em sonho e transporta a criança, por momentos, para um mundo em que não se convive com a dor e o sofrimento. Ainda, a atividade estabelece relação interpessoal entre o enfermeiro e a criança e de ambos com os personagens das histórias. Essa modalidade de cuidado auxilia na recuperação da criança doente, na aceitação da condição em que ela se encontra e na sua adaptação ao novo espaço, trazendo benefícios ao seu estado geral. É uma terapia que ajuda a liberar a fantasia e a afastar a tristeza e as sensações desagradáveis, e isso permite ao enfermeiro desenvolver o cuidado sensível.
\end{abstract}

Descritores: Enfermagem pediátrica; Criança hospitalizada; Relações enfermeiro - paciente

- Artigo recebido em 15/07/03 e aprovado em 15/04/04

\section{INTRODUÇÃO}

Este trabalho surgiu do desejo de compartilhar minha experiência como enfermeira voluntária em uma nova modalidade de atuação com crianças hospitalizadas, a qual tem sido utilizada como potencializadora para o enfoque de humanização em instituições hospitalares de grande complexidade, denominada 'Contador de Histórias'.

Para muitas pessoas, entrar em um hospital significa entrar em um lugar hostil, com profissionais que executam ações desconfortáveis, ruins e que causam dor. Desse modo, a pouca ênfase dada, em algumas instituições de saúde, ao calor humano no cuidado e no tratamento pode contribuir para retardar a recuperação da saúde, assim como reforçar no paciente idéias negativas sobre o ambiente hospitalar.

Nesse contexto, o enfermeiro, inserido na equipe multiprofissional, é quem mais bem conhece o paciente, por estar mais tempo ao seu lado, quer seja para executar procedimentos que o tratamento requeira, quer seja para ouvi-lo ou verificar a evolução das intervenções feitas por si ou pela equipe. Por isso, também, é o enfermeiro que, no processo de humanização do cuidado, pode oferecer maior contribuição.

Para complementar essa idéia, cabe destacar que toda atitude do profissional de enfermagem deve ter como meta a busca da dignidade humana, do respeito e valorização da vida e da qualidade do viver e, ainda, que a enfermagem, como profissão interativa, precisa repensar seus valores e atitudes na relação com os pacientes ${ }^{(1)}$.

* Trabalho realizado para a disciplina Enfermagem e a Prática Profissional, do Curso de Mestrado em Enfermagem da Universidade Federal do ParanáUFPR, pela primeira autora.

1 Enfermeira. Diretora de Enfermagem do Hospital Pequeno Príncipe de Curitiba. Membro do Núcleo de Estudos, Pesquisa e Extensão em Cuidado Humano de Enfermagem (NEPECHE/UFPR). E-mail: castanha@hpp.org.br

2 Enfermeira. Professora adjunta do Departamento de Enfermagem da UFPR. Doutora em enfermagem. Vice-coordenadora do NEPECHE/UFPR. (orientadora)

3 Enfermeira. Professora sênior do Programa de Pós-graduação em Enfermagem da UFPR. Doutora em enfermagem. Coordenadora do NEPECHE/UFPR. (co-orientadora) 
Em minha trajetória profissional como enfermeira, com mais de 20 anos de trabalho, a maioria dos quais desenvolvida num hospital pediátrico, sinto que, muitas vezes, passa despercebida ao próprio enfermeiro a possibilidade de desempenhar, no ambiente do hospital, ações que não sejam restritas ao cuidar técnico-administrativo e que possam trazer à criança doente o alento de que necessita para enfrentar o agravo à sua saúde, o tratamento e a permanência no ambiente hospitalar. Comumente, o relacionamento dela com os profissionais de enfermagem, nos hospitais, está ligado ao uniforme branco e às orientações referentes às ações de cuidado, que necessitam ser compreendidas pela própria criança e pela família, a fim de melhor superarem a doença e o tratamento instituído.

No dia-a-dia hospitalar, observase que ainda são poucos os enfermeiros que abordam com as crianças doentes temáticas que se distanciam da dimensão técnica do cuidado ou do cumprimento das rotinas hospitalares. No entanto, à medida que se busca aplicar a humanização do cuidado, novas oportunidades para tal fim podem ser visibilizadas pelos enfermeiros. Assim, é possível, com o passar do tempo, vislumbrar outras possibilidades de ajudar os pacientes, não só com o cuidado técnico, mas também com o cuidado humano e solidário.

Nesse horizonte, a modalidade Contador de Histórias surge como uma abordagem diferenciada, que permite ao enfermeiro disponibilizar parte de seu tempo com o paciente para ouvir, dialogar, sorrir e, principalmente, contar histórias. Esse instrumento propicia maior aproximação dele com o paciente e sua família, estreitando laços que poderão contribuir positivamente para a recuperação da saúde.

\section{COMO TUDO COMEÇOU...}

Com o surgimento do Projeto Biblioteca Viva em Hospitais ${ }^{(2)}$, iniciei minha participação na atividade de contar histórias, como convidada da instituição onde trabalho. Como a adesão deveria ser voluntária, minha primeira reação foi, por um momento, de hesitação, em que, para aceitar o convite, necessitei imaginar-me desempenhando aquele papel. Então, mais pela consideração de ter sido convidada do que pela própria visualização de uma nova possibilidade de ampliar a maneira de implementar o cuidado humano, aceitei. Contudo, existia grande inquietação no que se referia à maneira como seria vista a minha atitude dali para a frente, ou seja:

Você, com tantas atividades para desenvolver, ficar sentada na enfermaria, lendo histórias para crianças doentes? Se estão doentes, não querem saber de histórias! Como a equipe vai interpretar esse seu gesto?.

Apesar disso, resistindo a esses questionamentos, participei voluntariamente da capacitação que o projeto exigia para esse trabalho, a qual foi realizada na própria instituição, por profissionais qualificados para tal, e durou três dias, sendo que um período deles era destinado à prática e avaliação, no final. De posse daquelas orientações, fui a campo, seguindo uma escala preestabelecida pelos monitores. No dia anterior à leitura com as crianças, escolhia, geralmente, cinco títulos de histórias, que contemplassem várias idades infantis, a fim de motivar todos a ouvir a narrativa.

À medida que examinava a vasta biblioteca de livros de história de que o hospital dispõe, com a finalidade de selecionar os mais adequados, e realizava as leituras, esse novo mundo que eu descobria encantavame e seduzia-me, como já tinha ocorrido com outros que passaram por essa experiência:

Sem saber, descobríamos uma das funções essenciais do conto e, mais amplamente, da arte em geral, que é impor uma trégua ao combate entre os homens. $\mathrm{O}$ amor ganhava pele nova. Era gratuito. [...] Gratuito. Era bem assim que o ouvinte entendia. Um presente. Um momento fora dos momentos... imensamente leve, e o vento era nossa voz. Como preço dessa viagem, não se exigia nada dele, nem um tostão, não se pedia a menor compreensão. E não era nem mesmo uma recompensa. Aqui, tudo se passava no país da gratuidade. A gratuidade, que é a única moeda da arte ${ }^{(3)}$.

\section{O QUE DIZEM ALGUNS AUTORES SOBRE O ASSUNTO}

A criança, como ser em crescimento e desenvolvimento, tem curiosidade e permanente inquietude, as quais a colocam em contato com o mundo, com expectativas, sonhos e desejos. A doença interrompe essa trajetória, para impor um novo modo de vida, favorecendo a coexistência de sentimentos de perda das funções, incapacidades, restrições, distúrbios evolutivos, desequilíbrios emocionais e bloqueios, em seu caminhar para a própria construção de mundo.

Assim, auxiliar a criança doente a superar as dificuldades impostas pela doença exige do enfermeiro a utilização de ações criativas, com vistas a contribuir para o desenvolvimento saudável dessa criança. A doença altera a imagem simbólica que a criança tem de si mesma, causando alterações no seu processo de conhecer, compreender e experimentar o mundo. Desse modo, todas as formas de comunicação com a criança doente devem ser consideradas, ao se prestar cuidado diferenciado ${ }^{(4)}$.

Existem autores que atribuem grande importância ao imaginário, 
dizendo, por exemplo, que ele não é um elemento secundário do pensamento humano, mas a própria matriz do pensamento, pois entendem que a função fantástica do imaginário acompanha os empreendimentos mais concretos, modulando a ação social e estética. Ainda, ressaltam que, nessa organização imaginária, cabe à imagem - entendida como representação concreta, sensível, de um objetivo material ou ideal, presente ou ausente do ponto de vista preceptivo - papel eminente e relacional, o que evidencia o dinamismo do imaginário. Também, dizem que o mundo social é principalmente "idealidade", e essa idealidade é constituída por duas ordens que, em linguagem atual, poder-se-iam chamar realidade de signos e realidade de símbolos ${ }^{(5)}$.

Já, para outros, há tipos de idéias ou ideais de realidade, cujo papel é unicamente expressar as realidades às quais se aplicam, expressálas como são: trata-se dos conceitos propriamente ditos. Há outros tipos, ao contrário, cuja função é transfigurar as realidades a que se relacionam: são os ideais de valor. Sendo assim, o desejo é energia afetiva que investe nas representações simbólicas e inobserváveis em si mesmas. Afirmam ainda que o homem difere dos outros animais, porque a sua relação com o mundo não é imediata, é mediada por processos de pensamento. Entre o universo físico e o homem, existe a dimensão simbólica, que constitui o homem e o seu mundo. O homem não lida diretamente com as coisas e sim com símbolos, com os significados atribuídos às coisas pela sua cultura ${ }^{(6)}$.

Concordo com a segunda opinião, quando transporto essa simbologia para o cotidiano do cuidado à criança doente hospitalizada, pois, diante desse ser fragilizado e inseguro, existe uma dimensão que necessita ser explorada, pois ele está ali, à espera de amparo, carinho, so- lidariedade e, principalmente, de alguém que ative suas capacidades simbólicas. Perceber o ser criança doente acontece pelo encontro intersubjetivo entre o enfermeiro e a criança, no momento em que se estabelece o cuidado. Essa interação expande a vivência compartilhada em que se revela a expressividade dos envolvidos, considerando-se a criança doente o centro das ações.

O mundo do homem não é um mundo de fatos, é um mundo imaginário: a razão, a linguagem lógica e conceitual, a ciência, a arte, a religião e os sentimentos são dimensões imaginárias. Não há contraposição entre o real e o imaginário, porque $o$ real é construído socialmente. $\mathrm{O}$ real, portanto, é a interpretação que os homens atribuem à realidade, por meio das incessantes trocas entre as objetivações e as subjetivações que se fazem constantemente ${ }^{(6)}$.

Por conta disso, o ser humano experiencia dois mundos: aquele em que vive diariamente, controlado, e o que lhe permite o imaginário, o sonho acordado. Pelo sonho, pelo imaginário, o homem pode descobrir o que até agora sufocou, mas que está dentro de si e pode lhe ser útil. A partir disso, entende-se que, ao enfermeiro, cabe compreender que a recuperação da criança não depende apenas de fatores bioquímicos, mas também de o quanto ela se sente aceita ou rejeitada, à vontade ou constrangida, no ambiente hospitalar ${ }^{(7)}$.

Ainda, para melhor interpretar os atos verbo-gestuais do paciente, o profissional de saúde precisa se assumir como produtor consciente de linguagem e como elemento transformador, intérprete de mensagens. Ao efetivar-se a comunicação por meio da modalidade Contador de Histórias, o enfermeiro e a criança doente trocam suas experiências, sua cultura, seus valores, seu subjetivismo, seus interesses e suas expectativas. Desse modo, a percepção pessoal funciona como uma espécie de filtragem que condiciona a mensagem segundo a própria lente, de forma que o ser humano ouve e vê conforme a sua percepção ${ }^{(8)}$.

Comentando as vantagens da literatura infantil, autores enfatizam que a literatura infantil visa a minimizar os efeitos nocivos da hospitalização, estimulando a criança a desenvolver o seu potencial imaginário e criativo, na procura de distraíla, no que se refere à sua doença, como também incentivá-la ao gosto e hábito pela leitura. O hábito de aproveitar o momento da internação para ajudar a criança a exercitar sua imaginação e sua cultura é uma nova "ferramenta" de cuidado. Em face da possibilidade de restabelecer o equilíbrio alterado no decorrer do internamento, mesmo em situação de declínio do organismo, a imaginação, em termos motivacionais, torna-se a mola propulsora de modificações de comportamento interior com reflexo no exterior ${ }^{(9)}$.

Dessa forma, além de acreditar no poder da história e na magia e atração que exerce o contador sobre seus ouvintes, muitos estudos mencionam a importância da literatura para o desenvolvimento infantil, por ela ser recreativa, educativa, instrutiva, afetiva (alarga horizontes, estimula a criatividade, cria hábitos, desperta emoções, valoriza sentimentos) e física (ajuda na recuperação de crianças enfermas e hospitalizadas). Ela estimula, também, a socialização e desenvolve a atenção e a disciplina ${ }^{(10)}$.

\section{CONTAR HISTÓRIAS E CUIDAR}

O cenário hospitalar é geralmente desconhecido pela criança. Ela, uma vez internada, passa a conviver com outras crianças doentes, em diferentes estágios de enfermidade, sendo assim transportada para um ambiente associado ao sofrimento e, algumas vezes, à morte. Ao ser hospitalizada, a criança é afastada abruptamente de sua família, de sua casa, 
de seus amigos e de seus brinquedos, o que gera situações de grande insegurança. A hospitalização prolongada diminui a convivência da criança com a família, os amigos e os colegas da escola, e isso pode excluí-la também da possibilidade de contato com o universo imaginário. Entretanto, essa situação vem sendo modificada, mediante inúmeras iniciativas já adotadas em alguns hospitais do Brasil, com a ajuda de voluntários e do próprio Ministério da Saúde, por meio da implementação do Projeto Biblioteca Viva em Hospitais.

Poder falar das histórias, identificar-se com os personagens, rir e se emocionar com os contos e as imagens contidas nos livros proporciona à criança espaço para imaginar e brincar, mesmo ela estando imobilizada no leito. Ressalta ainda que, lendo e contando histórias para as crianças, os adultos também estarão ampliando seu universo cultural e sua formação como leitor ${ }^{(2)}$.

Brincar é necessidade da criança em todas as etapas de seu desenvolvimento. Considerando-se esse pressuposto, foram criadas as brinquedotecas e as salas de recreação em vários hospitais do Brasil. Da mesma forma, a leitura de histórias e a troca de livros com um adulto é elemento fundamental na socialização e desenvolvimento saudável de todas as crianças ${ }^{(2)}$.

Estando o enfermeiro inserido nesse contexto de cuidar, ele pode utilizar também diferentes instrumentos de cuidado, como a criatividade e a comunicação, para ajudar seus pequenos pacientes a descobrir mundos e sentidos novos, transpondo assim as barreiras de certos medos e inseguranças que o ambiente hospitalar desperta.

A criatividade pode ser conceituada como sendo uma necessidade humana e social, cuja utilização gera o progresso, o desenvolvimento e a evolução da humanidade, é uma tendência natural que impele o indiví- duo à auto-realização ${ }^{(11)}$. Tanto o enfermeiro quanto a criança, como parceiros de leitura, além da imaginação criativa, devem utilizar a comunicação, posto que ela gera troca de experiências, promove o relacionamento entre as pessoas e ajuda na busca de soluções. Então, é importante que, no ambiente hospitalar, no qual culturalmente prevalece a dor e o sofrimento, coloque-se algo novo para a criança, criando-se a oportunidade para ela sonhar colorido.

A experiência que relato aqui demonstrou grande aceitabilidade da criança, mesmo pequena, para ouvir a história e ver suas figuras no livro. Constatei que o cultivo do imaginário ajuda a criança a 'esquecer' sua dor e a sonhar com algo bom durante certo tempo, pois, enquanto contava ou lia as histórias, observei muitas crianças sorrindo e até dormindo. Então, entendo, pela experiência, que, quando a criança usa sua imaginação de forma positiva e criativa, no espaço hospitalar, ela aceita melhor o ambiente e torna-se mais colaborativa, pois percebe que o enfermeiro não desempenha apenas ações que geram dor, mas também conta histórias, assim, ele incentiva o contato dela com o imaginário, e isso se torna prazeroso e agradável.

Essa interação mediada pela leitura facilita a integração das crianças e de sua família com a equipe hospitalar, proporcionando também alívio de tensões e fomentando mudanças nas ações e reações das crianças. Dessa maneira, é significativo que o enfermeiro ajude seus pacientes a integrar as emoções geradas pelo imaginário, a fim de tornálas amigas, geradoras de energia, e não o contrário.

Para contar histórias, é necessário seguir determinada metodologia. As seções de leitura, quanto a dia, hora e local, são programadas pelo próprio enfermeiro. Todavia, essa agenda deve ser conhecida pelos coordenadores do projeto dentro do hospital, porque eles monitoram os relatórios gerados, que precisam ser feitos ao final de cada seção de leitura, nos quais são descritos os livros utilizados e o número de crianças participantes. São esses mesmos coordenadores os responsáveis por capacitar os funcionários de qualquer setor que desejam ser contadores de histórias voluntários.

Nesse experimento, segui, além das orientações dadas pelos coordenadores internos, alguns cuidados ${ }^{(10)}$ a tomar antes de ler ou contar as histórias, como: verificar o local (quarto, enfermaria, UTI, corredor, sala), o horário e as acomodações; conhecer o público a que se destina a seção e o enredo da história; lembrar de enfatizar os pontos emocionantes da história, por meio de variações de tonalidades de voz e pausas oportunas; de não romper o fluxo da narrativa com conselhos e explicações; e de não perder o fio da meada quando estiver usando o livro ou outro material ilustrativo.

Ainda, dar atenção ao fato de que, independentemente do local, os ouvintes devem estar bem acordados, dispostos em círculo, sentados no chão, em tapetes ou almofadas, em ambiente com conforto térmico, livre de outros barulhos, em horário adequado ${ }^{(10)}$. Contar histórias para crianças cansadas, com fome e com vontade de ir ao banheiro não é nada gratificante.

Ainda, a duração da narrativa também deve ser adequada: de 5 a 10 minutos para as crianças menores e de 15 a 20 minutos para as maiores. A repetição da história, se solicitada, deve ser sempre atendida. Outra história não deve ser iniciada sem intervalo. Uma conversa preparatória que motive para a nova vivência é muito bem-vinda. Qualquer pessoa que saiba ler adequadamente e que goste de trabalhar com literatura e pessoas (crianças e adultos) pode e deve participar dessa experiência. 
Outro aspecto importante para o êxito da seção é o tom de voz usado, que deve se adequar à compreensão do que é dito, a fim de evitarse a monotonia; também, deve-se observar a respiração correta, fazer pausa de acordo com a pontuação, variar a entonação, frisando-se os pontos mais importantes, e usar a expressão adequada em cada frase. Não existe comunicação verbal sozinha, a mensagem transmitida é sempre uma interação entre a comunicação verbal e a não-verbal ${ }^{(8)}$.

Quando se possibilita um momento de livre exploração dos livros - olhar, folhear, ler ou reler - ou, ainda, quando se fica à disposição das crianças para acompanhá-las ou contar as histórias, nota-se uma série de fatos, como, por exemplo, que as crianças são capazes de compreender, pensar e criar muito mais do que se imagina ${ }^{(10)}$.

Muitas vezes, nos ambientes de saúde, esquece-se, até com certa facilidade, que ter um problema de saúde não necessariamente significa que todo o indivíduo esteja doente. Por vezes, sua imaginação mais bem ‘ocupada' poderia ajudá-lo a enfrentar com mais serenidade sua condição. Nesse sentido:

[...] nenhum universo é mais vasto que a imaginação. Tudo passa primeiro por ela: todas as artes, filosofias, invenções, assim como toda mudança e desvio do dia-adia. A imaginação é o melhor amigo da mente, o burilador de sonhos e a companhia feliz da vida. Através da história, várias vezes interrompemos atividades externas (ou as fizemos repetidamente) para entrar nas regiões infinitas da mente, desde devaneios casuais até meditações disciplinadas ${ }^{(12)}$.

A imaginação existe em cada pessoa e, assim como o corpo físico, a imaginação pode tornar-se flácida, se não exercitada e apreciada. As pessoas costumam abando- nar seus interesses quando se sentem tristes ou ansiosas, entretanto, é nesse momento que se deve listar o valor terapêutico dos passatempos. Trazer a arte do cultivo da imaginação para a prática de saúde ajuda o profissional a ser melhor, e o faz também um ser humano melhor ${ }^{(12)}$.

\section{CONSIDERAÇÕES FINAIS}

Como conclusão geral da experiência que relatei, posso dizer que utilizar essa forma de cuidar é muito importante, pois é como tirar breves férias das preocupações do diaa-dia e se pôr a voar em busca de um mundo onde as soluções para os problemas do cotidiano podem ser mais facilmente encontradas.

É reconfortante ver a alegria das crianças que chegam até você sem medo, acreditando que você está ali para elas, para ajudá-las e não para 'judiar' delas - como elas em geral vêem os enfermeiros -, que você é quem as ajuda a abrir as portas da imaginação e também a ver além das letras e das figuras. O que perpassa no momento em que se media a leitura de uma história é uma sensação de bem-estar.

É interessante o fato de sentarse com duas, três, cinco ou mais crianças, nas enfermarias, nos ambulatórios ou mesmo ao lado dos berços, e sentir-se na sua 'altura', tentando ver o mundo e as coisas com os olhos dos pequenos. Essa experiência proporcionou-me ter a certeza de que a maior beneficiada foi eu mesma. Por isso, concordo com a afirmação de que a arte, a natureza e a imaginação são fundamentais para o cuidado com a saúde ${ }^{(12)}$.

Participar desse projeto trouxe um olhar novo sobre outras formas de prestar cuidados e oportunidades de influenciar mentes para que, ao longo de suas existências, sejam pessoas mais felizes e saudáveis em seus pensamentos e hábitos de vida.

Essa experiência deixou-me mais sensível em relação às necessi- dades de sonhar e imaginar que toda a criança tem, independentemente de sua condição social ou de saúde. Aliás, fez-me até pensar que cuidar desse fator na criança é utilizar as possibilidades que o cuidado sensível e o cuidado-arte na enfermagem permitem.

\section{REFERÊNCIAS}

1. Bettinelli LA. A solidariedade no cuidado: dimensão e sentido da vida [tese doutorado]. Florianópolis: Programa de Pós Graduação em Enfermagem, Universidade Federal de Santa Catarina; 2002.

2. Brasil. Ministério da Saúde. Projeto Biblioteca Viva em Hospitais. [on line] Brasília; 2003. Disponível em: http:/ www. ensp. fiocruz.br/public/radis/ vasmont/BibViva.html.

3. Pennac D. Material de apoio para a formação de multiplicadores do Projeto Biblioteca Viva em Hospitais.Brasília: Ministério da Saúde; 2002.

4. Karl IS. O ser enfermeira e o ser criança: diálogo vivido sob o olhar de Paterson e Zderad. [dissertação mestrado]. Porto Alegre: Programa de Pós-graduação em Enfermagem, Universidade Federal do Rio Grande do Sul; 2002.

5. Teixeira MCSA. Dinâmica do imaginário e a trajetória da cultura: re-significando o social. In: Conferência do Imaginário e das Representações Sociais da Educação Física, Esporte e Lazer. LIDERES/UGF. [online]. Rio Janeiro; 2001. Disponível em: http://www. pro.br livros textos_dis ponível. html.

6. Cemin AB. Entre o cristal e a fumaça: afinal o que é o imaginário?[online]. Rondônia; 2001. Disponível em: http:/ /www.unir.br./ cei artigo1. html.

7. Moran JM. Aprendemos com o imaginário[online]. São Paulo; 2003. Disponível em: http:www. eca. usp.br/prof./ moran.imaginar.htm>. 
8. Silva MJP. Comunicação tem remédio: a comunicação nas relações interpessoais em saúde. São Paulo: Gente; 1996.

9. Matos ELM, Muggiati MMTF. Pedagogia hospitalar. Curitiba: Universitária Champagnat; 2001.
10. Souza LMS, Dupas MA. Ler é prazer: os projetos de incentivo à leitura da biblioteca comunitária da UFSCar. [online]. São Carlos; 2000. Disponível em:http//www.snbu.bvs.br/snbu 2000/poster.html.
11. Cianciarullo TI. Um desafio para a qualidade de assistência. São Paulo: Atheneu; 2001.

12. Adams P, Mylander M. A terapia do amor. Rio de Janeiro: Mondrin; 2002.
Castanha ML, Lacerda MR, Zagonel IPS. [Is the hospital a place for caring about imagination?] Acta Paul Enferm 2005; 18(1):94-9.

ABSTRACT: This paper discloses an experience report on nurse's work as caregiver, in which he makes use of 'storyteller' modality in a children's hospital. As a caring tool, such activity shows dynamism of children's imaginary world, since it changes their experiences into dream through the fantasy that the story brings and carries them away for some moments to a world where there is no pain and suffering. Also, this activity helps to establish interpersonal relationship between nurse and children, and between both of them and the story characters. Such caring modality helps sick children's recovery, acceptance of their illness condition and adjustment to the new environment, that is, the hospital. All this brings benefits to their health state as a whole. So, storytelling is ancillary therapy to set fantasy free and to keep distance from sadness and unpleasant sensations, and this enables nurse to achieve sensitive care.

Descriptors: Pediatric nursing; Child, hospitalized; Nurse - patient relations
Castanha ML, Lacerda MR, Zagonel IPS. [Hospital:¿un lugar para cuidar de lo imaginario?] Acta Paul Enferm 2005; 18(1):94-9

RESUMEN: Aborda un relato de experiencias sobre la actuación del enfermero como cuidador, utilizando la modalidad "Contador de Historias" en un hospital infantil. En cuanto instrumento para cuidados, demuestra el dinamismo del imaginario de un niño, pues transforma la realidad vivida en sueño, a través de la fantasía de la historia y es transportada, por momentos, a un mundo que convive con el dolor y el sufrimiento. Establece la relación interpersonal entre enfermero-niño y los personajes de las historias. Esa modalidad de cuidados auxilia en la recuperación, aceptación de la condición en que se encuentra, adaptación al nuevo espacio y trae beneficios al estado general del niño enfermo. Funciona como terapia que ayuda a liberar la fantasía y eliminar la tristeza y las sensaciones desagradables, permitiendo al enfermero desarrollar el cuidado sensible.

Descriptores: Enfermería pediátrica; Niño hospitalizado; Relaciones enfermero - paciente 